\title{
Acertos e dificuldades do Manifesto Comunista
}

RUY FAUSTO

C6 A HISTORIA DE TODA sociedade até hoje é a história de luta de classes". "As

A idéias dominantes de uma época sempre foram as idéias das classes dominantes". "O poder de Estado moderno não é mais do que um comitê, que administra os negócios comuns do conjunto da classe burguesa". "Os trabalhadores não têm pátria". "[Numa revolução comunista], os proletários não têm nada a perder se não as suas cadeias". "Em lugar da velha sociedade burguesa, com suas classes e suas oposições de classes, surge uma associação na qual o livre desenvolvimento de cada um é a condição para o livre desenvolvimento de todos" (1).

O Manifesto é conhecido, antes de mais nada, por algumas frases famosas. Algumas delas, como aquela que fala do poder de Estado, são muito verdadeiras; outras, como a que considera os trabalhadores como "sem-pátria” não são literalmente verdadeiras e se legitimariam antes no interior de um projeto político; outras ainda, como aquela com que se abre o texto, são "problemáticas".

A história não é - apenas - a história da luta de luta de classes, pelo menos por três razóes. Uma, indicada por Engels na edição inglesa de 1888, é que parece haver existido sociedades sem antagonismos pelo menos comparáveis com os antagonismos modernos; outra é a de que as oposiçóes existentes na maioria das sociedades anteriores ao modo de produção capitalista não foram a rigor oposiçóes de "classes" (o conceito de classe, como já diz um texto da Ideologia Alemã, só se aplica rigorosamente ao modo de produção capitalista); o terceiro é o de que, como Marx e principalmente $O$ Capital ensinam abundantemente, a história não é só luta, ela é também inércia. A história até hoje é também história das "estruturas", em relação às quais os indivíduos não são "agentes-sujeitos" mas suportes. (A tensão entre "sujeitos" e suportes, dupla função das individualidades, é um dos achados dialéticos de Marx, infelizmente reduzido ao imperialismo das práticas ou ao imperialismo das estruturas, ambos no registro do entendimento.) $\mathrm{O}$ próprio Manifesto, que por mais de uma razão (por ser um manifesto, e por pertencer a um período determinado do pensamento de Marx, do qual falarei mais adiante) privilegia as práticas, refere- 
se de qualquer forma à função de suportes: "O progresso da indústria, cujo suporte (Träger) sem vontade (willenlos) e sem resistência (widerstandlos) é a burguesia (...)" (W. 4: 474; M: 77-78). Há problemas assim relativamente às lutas, às classes e às lutas de classes, mas a frase com que se abre o Manifesto náo é propriamente falsa: o marxismo não é uma teoria geral da história, é uma crítica ao capitalismo que pressupóe apenas (em sentido dialético: o pressuposto é ao mesmo tempo posto e não posto) um esquema geral da história. As dificuldades, veremos, são outras.

O Manifesto pode ser apreciado de um ponto de vista estritamente teórico ou de uma perspectiva política (claro que há teoria política, mas aqui tomo "política" num sentido mais estreito). Num outro plano, ele pode ser lido ou como momento da história das lutas socialistas, ou como momento da história do pensamento e da prática do seu autor principal (ou de seus autores).

Enquanto momento da história do pensamento de Marx, o Manifesto, independentemente do gênero a que pertence, corresponde bem nitidamente a um período de transiçáo de que faz parte igualmente, entre outros textos, a Ideologia Alemã. As obras desse período caracterizam-se por certos traços peculiares que as distinguem, por um lado, do momento dos Manuscritos de $1844 \mathrm{e}$, por outro, das obras de maturidade, sobretudo $O$ Capital e os Grundisse. No momento dos Manuscritos de 44, Marx escreve como filósofo (mesmo se filósofo não-filósofo à maneira de Feuerbach - o texto é feuerbachiano mas como um componente hegeliano); na época de transiçấo que consideramos, o discurso de Marx se pretende, pelo contrário, claramente antifilosófico; e na época da maturidade poder-se-ia falar em "supressão" em sentido hegeliano, supressão-conservação da filosofia.

Além de antifilosófico, nas suas intençōes pelo menos, o discurso da transição tende a uma espécie de historicismo: a teoria e todas as formas de consciência aparecem mais ou menos no nível da história (enquanto em 44 elas se elevam como uma espécie de transcendental; na maturidade, tem-se uma posição intermediária).

Finalmente, o pensamento da transiçáo tende a evitar todo tipo de totalização. Em particular, faz-se um imenso esforço para apresentar a revolução como uma revolução do mesmo tipo genérico das outras, e que, se encerra a história da exploração, é apenas porque o modo de produção burguês é o último. (Nos Manuscritos de 44, a revolução é pensada como visando antes o conjunto da "pré-história"; enquanto n'O Capital e nos Grundisse, o alvo é, sem dúvida, o capitalismo, mas pensado como universal concreto, que contém em si mesmo, de certo modo, o conjunto do desenvolvimento anterior. No período 
de transição, em vez da universalidade, tem-se antes a generalidade): "O que caracteriza o comunismo não é a aboliçăo da propriedade em geral, mas a aboliçáo da propriedade burguesa./ Mas a moderna propriedade burguesa é a última e a mais perfeita expressão da fabricaçáo e apropriação de produtos, que se baseia em oposiçóes de classes, na exploração de uns pelos outros [da maioria pela minoria: Engels, 1888]./ Nesse sentido, os comunistas podem resumir sua teoria nessa única expressão: supressão (Aufbebung) da propriedade privada" (W. 4: 474; M: 80, grifado por RF) (2).

Como momento da história da crítica socialista, o Manifesto - como em maior ou menor medida Marx em geral - traz a novidade de fazer da autodeterminaçáo do proletariado o motor da transformaçáo revolucionária, e fazer da revoluçáo um processo cujo sujeito é a maioria: "Todos os movimentos precedentes foram movimentos de minorias ou no interesse de minorias. $O$ movimento proletário é o movimento autônomo (selbständige) da imensa maioria no interesse da imensa maioria" (W. 4: 473; M: 77, grifado por RF). Do mesmo modo, lê-se mais adiante, a propósito dos socialistas utópicos: "Eles não vêm nenhuma auto-atividade (Selbsttätigkeit) histórica da parte do proletariado, nenhum movimento político que lhe seja próprio"(W. 4: 490; M: 96, grifado por RF). Essa perspectiva rompe com as formas tradicionais de pensar o processo de ruptura da velha sociedade. Nessas formas tem-se ou a figura do educador, ou a figura do ditador (3), de qualquer forma, um socialismo "de cima", que como diz a terceira tese sobre Feuerbach, tende a separar a sociedade em duas partes. A referência clássica do socialismo pré-marxista era freqüentemente o Discurso sobre a origem da desigualdade de Rousseau, sem que se supusesse a possibilidade do contrato (é duvidoso que o próprio Rousseau o supusesse) no interior de uma sociedade corrompida. $O$ recurso à figura do legislador rousseauista é insuficiente. Necessita-se de um "mestre", ditador ou educador. Mas quem educará o educador? A novidade de Marx é a de ter encontrado um elemento inerente à sociedade corrompida, capaz de auto-educação, o qual se auto-educando poderia reconstruir toda a ordem social.

O Manifesto foi escrito em nome da Liga dos Comunistas, organizaçáo de artesãos alemães que sucede à Liga dos Justos cuja direção se trasladara de Paris a Londres. Publicado em Londres, em alemão, algumas semanas antes da eclosão da Revolução de 48 na França, ele pretende exprimir as posiçóes "dos comunistas".

Em termos organizatórios, se o Manifesto afirma que "os comunistas não constituem (sind) nenbum partido particular diante dos outros partidos operários (Arbeiterparteien)" (W. 4: 474; M: 79, grifado por RF) ele diz ao mesmo 
tempo que "os comunistas se distinguem dos outros partidos proletários por (...)".( $i b$. , grifado por RF) e que "o objetivo imediato dos comunistas é o mesmo que o de todos os demais partidos proletários" (W. 4: 474; M: 80, grifado por RF). Na realidade Marx parece propor a estratégia do partido dentro de um partido, de que seriam exemplos a atividade da seção londrina da Liga no interior do cartismo, mediante uma outra organizaçáo intermediária, e a da Social Reform Association dos comunistas alemães de New York no interior da National Reform Association (a qual é caracterizada pelo Manifesto, junto com o cartismo, como um partido operário ou dos trabalhadores (Arbeiterpartei) (ver W. 4: 492; M: 98) (4).

Do ponto de vista tático, o Manifesto tem a particularidade de propor para a Alemanha uma luta "junto com a burguesia" - ainda que com a ressalva: "sempre que ela se conduzir como revolucionária" - luta cujos adversários são "a monarquia absoluta, a propriedade fundiária feudal e a pequena burguesia"(W. 4: 492; M: 99, grifado por RF). Como assinala Hal Draper (5), essa posiçāo é diferente da que exprimira Engels pouco antes, e da que adotariam Marx e Engels imediatamente depois. O Manifesto afirma "que o primeiro passo da revolução operária é (...) a conquista da democracia (die Erkämpfung der Demokratie)" (W. 4: 481; M: 86). Mas “a democracia" representava, para Engels, a aliança "do proletariado, do pequeno campesinato e da pequena burguesia" (Engels, "Os Comunistas e Karl Heinzen", W. 4: 312, grifado por RF, citado por Hal Draper, op. cit., II: 186, cf. id.: 190). E, segundo Draper, já num panfleto escrito pelos dois autores um mês depois da publicação do Manifesto, eles se manifestam favoravelmente ao bloco das três classes "democráticas", tal como o definira Engels (6).

Quanto à aliança com a burguesia ela vai igualmente desaparecendo como proposta. Na célebre Mensagem da dirę̧ão central [da Liga dos Comunistas] à Liga, de março de 1850, o aliado eventual, de resto duramente criticado, é a pequena-burguesia, não a burguesia. A perspectiva do Manifesto é assim, talvez, excepcionalmente "progressista", no mau sentido do termo (a experiência de 48 teria tido o papel de reforçar a crítica), mas essa perspectiva estratégica tem alguma ambigüidade (cito agora o texto completo): "Já vimos acima que o primeiro passo na revoluçáo operária ou dos trabalhadores (Arbeiterrevolution) é a elevação do proletariado a classe dominante, a conquista da democracia" (p. 481-486). É possível que o texto pense em três momentos: vitória da burguesia com o apoio do proletariado, vitória da "democracia" (mas excluída a pequena burguesia, o proletariado talvez só organizasse forças políticas e não propriamente sociais na "democracia"), dominação progressiva do proletariado. De qualquer maneira, como nos textos anteriores e posteriores, o processo é de "revolu- 
ção permanente" (expressão com que Marx encerra a Mensagem de março de 1850). Para o caso do Manifesto, ela toma a seguinte forma: é preciso não deixar de desenvolver em nenhum instante nos operários "uma consciência a mais clara possível da oposição hostil entre burguesia e proletariado", para que utilizando as condiçōes criadas pela dominação da burguesia "imediatamente após a derrubada das classes reacionárias na Alemanha, comece imediatamente a luta contra a burguesia" (W. 4: 493; M: 99).

Voltando aos problemas teóricos. Se o texto do Manifesto pertence a uma fase que tem alguma coisa de "historicista" (7), a dialética não está inteiramente ausente dele. Um exemplo é o emprego da noção de classe. Em vários momentos (8) fala-se em "organização do proletariado em classe" (zur Klasse), o que levou os críticos do entendimento a quebrarem a cabeça. $O$ proletariado nãoorganizado já não é uma classe? O resultado foi que, de parte de certos althusserianos, denunciou-se a falta de rigor do Manifesto. Na realidade, a expressão implica que antes de ser organizada a classe é e não classe. $O$ estatuto da classe é nesse "momento", que pode ser recorrente, contraditório. A classe só é classe quando posta como classe. $\mathrm{O}$ que, em termos filosóficos, significa um escândalo para entendimento: contra o que afirma Kant, na crítica do argumento ontológico, a posição não se acrescenta à determinação, ela lhe é constitutiva. (Com algum pedantismo, mas também com alguma verdade, dir-se-ia que para entender bem a lógica do Manifesto é preciso ter lido Santo Anselmo e a sua formulação clássica do argumento ontológico...) De qualquer forma é verdade que mesmo nesse texto "prático" (ou talvez por ser ele um texto prático, as duas coisas às vezes convergem), há um investimento considerável - embora limitado com relação a outros textos - das "maquinas de guerra" do idealismo alemão).

Quanto à frase "mas toda luta de classes é uma luta política" (W. 4: 471; M: 75), frase que representou para o entendimento o escândalo máximo, ela provavelmente deve ser entendida como se o "é" não exprimisse a predicação usual, mas sim o que chamei de juízo de reflexão: "toda luta de classes é ... uma luta política", ou seja, toda luta de classes se reflete em, ou se torna, luta política.

Outro momento dialético é o movimento barbárie/civilização. Limitome aqui ao mais belo texto. A crise, que nas obras posteriores é pensada como irrupção da memória posta do sistema, é vista aqui no contexto da idéia de uma civilização afetada de barbárie: "Nas crises irrompe uma epidemia social, que em todas as épocas precedentes teria parecido um absurdo (Widersinn) - a epidemia da superprodução. A sociedade vê-se repentinamente reconduzida a um estado de barbárie momentânea: é como se uma [situação de] miséria (Hungernot) ou uma guerra geral de extermínio houvesse suprimido todos os meios de sub- 
sistência; a indústria, o comércio, parecem aniquilados, e por quê? Porque a sociedade possuiu demasiada civilização (zuviel Zivilisation), demasiados meios de subsistência, demasiada indústria, demasiado comércio" (W. 4: 468; M: 72, grifado por RF).

Fazendo um balanço, se posso dizer assim, quais são os acertos e os desacertos do Manifesto? $\mathrm{O}$ problema é complicado porque implica, de uma forma ou de outra, uma avaliação global do marxismo.

Já falei da grande densidade teórica do texto. A novidade de Marx é ter investido em ciência, e aqui em política, a herança lógica muito rica e complexa do idealismo alemão. Apesar de os limites assinalados, não conheço manifesto político algum que incorpore desse modo um legado lógico-filosófico daquele porte.

É costume criticar o Manifesto porque ele supõe uma simplificação das oposiçôes de classe (ver W. 4: 463; M: 67) que não teria ocorrido. A observação me parece válida, mesmo se há uma discussão a respeito do alcance da temática da decadência das classes médias (ver W. 4: 460-461; M: 73) (9). Mas as observaçōes críticas que farei mais adiante não enveredarão por aí.

A análise da história do capitalismo é sólida, e está bem mais próxima d' $O$ Capital que a da Ideologia Alemã (10). Nela se reconhecem a história material e a história formal do modo de produçáo capitalista, e o capital já é tratado como potência (Macht) social (ver W. 4: 476; M: 81). O modo de produção capitalista (a noção de "modo de produção" encontra-se, por exemplo, em W. 4: 466; M: 70) (11) e aparece numa passagem clássica efetuando uma espécie de desencantamento do mundo. Mas o paralelo com Weber é em parte enganoso. O universo do capitalismo é para Marx um universo encantado; só que o seu encanto é o das abstrações desencadeadas. É como se houvesse um desencantamento "semântico" do mundo, mas não um desencantamento "sintático" (o que Weber parece ter perdido de vista) (12). Cito o texto, muito conhecido embora: "Onde quer que tenha chegado ao poder, a burguesia destruiu todas as relaçôes feudais, patriarcais, idílicas. Dilacerou impiedosamente os laços feudais multicores que ligavam o ser humano aos seus superiores naturais, e não deixou subsistir entre homem e homem outro vínculo que não o interesse nu e cru (das nackte Interesse), o insensível “pagamento em dinheiro". Afogou nas águas gélidas do cálculo egoísta os sagrados frêmitos da exaltação religiosa, do entusiasmo cavalheiresco, do sentimentalismo pequeno-burguês (spiessbïrgerlich)" (W. 4: 464; M: 68).

$\mathrm{O}$ fato de o texto ter assinalado a tendência cosmopolita e globalizante do sistema (ver W. 4: 466; M: 69-70), inclusive no plano da "produção espiritual", 
assim como a tendência a universalizar a relação salarial (ver W. 4: 465; M: 69), são pontos fortes e atuais. Já falei das crises. Politicamente, a ênfase no automovimento do proletariado, e na revolução das maiorias, apesar das opinióes correntes, fazem do Manifesto um texto que, em primeira instância, é dificilmente compatível com a leitura da política marxista que farão alguns no século XX: Creio que a política do Manifesto - que não fala em "ditadura do proletariado", só em "dominação" (Herrschaft) do proletariado, mas não é isso o essencial - é em primeira instância incompativel com o vanguardismo bolchevique. Do Manifesto é difícil tirar a idéia de partido único. Entretanto, como veremos a partir de uma outra vertente, ele pode dar armas a um projeto antidemocrático (nos limites desse texto, diria que são os direitos da "minoria" não-revolucionária - não necessariamente contra-revolucionária - que ficam vulneráveis. Mas a partir dessa brecha, tudo se torna possível, mesmo a autodeterminação do proletariado acaba sendo ameaçada).

As dificuldades do Manifesto são em geral dificuldades do marxismo, embora a fase particular do pensamento de Marx a que o texto pertence talvez as tenha agravado. Retomo aqui, no contexto do Manifesto, uma linha de pensamento que desenvolvi no posfácio sobre a política de Marx do meu livro $O$ capital e a lógica de Hegel (dialética marxista, dialética hegeliana) (13).

A dificuldade do Manifesto - como a meu ver, em maior ou menor medida, do marxismo em geral - está em ter pensado que deve haver uma passagem "catastrófica" do capitalismo ao socialismo. Não me refiro especificamente ao problema da revolução violenta em oposição à transição pacífica, embora a questão a discutir tenha efeitos sobre ele. Quero dizer que Marx não pensa que possa haver alguma continuidade de formas na passagem do modo de produçáo capitalista ao que ele chama de comunismo. Isso significa que, no plano das formas (políticas ou econômicas), ele não vê nenhum tipo de acumulação. $O$ comunismo deve destruir as formas capitalistas e construir novas formas (se há progresso político no capitalismo é essencialmente porque - ou no sentido de que - ele permite a eclosão da revolução) (14). Essas características remetem a uma noção muito estreita de forma. As formas aparecem fundamentalmente como expressões ilusórias, sem densidade própria e, o que é importante, sem um mínimo de verdade própria. A ideologia é vista menos como uma forma contraditória do que como uma forma negativa em sentido corrente. Vai na mesma direção a idéia de uma história com "terceiro excluído" (isto é, sem "terceiro"). Há, de um lado, o modo de produção capitalista; de outro, o comunismo como movimento futuro. Mesmo se o processo não é considerado como fatal (o texto diz que ele é inevitável - ver W. 4: 474; M: 78 - mas o problema náo é bem esse), não se pensa a possibilidade da emergência de outras formas de exploraçáo e de domi- 
nação. Ora, o século parece ter mostrado essa possibilidade. E o texto Manifesto, pensado uma passagem "catastrófica" (no sentido indicado) do capitalismo ao que chamamos de socialismo, recusando qualquer progresso político que não seja o da criação de condiçōes favoráveis à revolução, reduzindo as formas jurídicas e ideológicas a pouco mais do que uma tênue camada ilusória, produz uma espécie do que chamei de "ponto cego" no marxismo, que o torna susceptível de uma utilização relativamente cômoda como ideologia das sociedades burocráticas do século XX.

Vejamos alguns textos: "Os proletários nada têm de seu para salvaguardar, têm de destruir toda segurança privada (Privatsicherheit) e todas as garantias privadas (Privatversicherungen) existentes até aqui" (W. 4: 472; M: 76, grifado por RF). Texto extremamente perigoso, a meu ver, e que pode facilmente ser instrumentalizado por poderes burocráticos. Abuso de leitura por parte desse poderes? Sem dúvida, mas não inteiramente. Muito dificilmente Marx seria favorável aos regimes burocráticos. Mas o problema é que ele não viu o risco da emergência desses regimes (cf. sua discussão com Bakunin). Por isso também não viu a importância das garantias jurídicas obtidas.

"As leis, a moral, a religião são para [o proletário] igualmente tantos preconceitos burgueses, por trás dos quais se ocultam tantos interesses burgueses" (W. 4: 472; M: 76). Interessam-me aqui as leis e a moral (embora evidentemente seja defensor da liberdade religiosa). Marx e Engels não condenam estas ou aquelas leis, nem esta ou aquela moral. $O$ problema é discutido explicitamente no texto, e tem a ver com a questão da generalidade tratada anteriormente (mas mesmo com a universalidade introduzida pelas obras de maturidade, o problema subsiste). Trata-se de erradicar, a longo prazo sem dúvida, mas erradicar, de qualquer modo, o direito e a moral. Com isso, imediatamente, direito e moral se tornam suspeitos. São expressóes da história da exploração. De novo a convergência entre os interesses burocráticos e o discurso de Marx (mesmo se Marx - e Engels - visavam de fato o capitalismo) é, a meu ver, evidente. Quem quer que faça apelo às leis ou à ética diante desses poderes pode facilmente ser neutralizado, com algum abuso é certo, mas também com uma semijustificação, a partir desses textos.

Marx pensa numa situação final de transparência social, em que não haverá mais Estado. Os textos são conhecidos: "Quando no curso do desenvolvimento as diferenças de classe desaparecerem e toda a produção se concentrar nas mãos dos indivíduos associados [observar que ele faz dos indivíduos os sujeitos, contra todo "holismo" (RF)], o poder público (die äffentliche Gewalt) perderá o caráter político (politscher Charakter). O poder político em sentido 
próprio é o poder organizado de uma classe para opressão de outra" (W. 4: 482: M: 87). Muito bem, "poder público" mas não poder político, já que este é identificado com a opressão de classe... A dificuldade é que Marx e Engels supóem o desaparecimento do direito e de todo sistema de formas. Além do caráter provavelmente utópico do projeto (falarei disso logo adiante), essa perspectiva lança suspeita sobre a idéia de forma jurídica em geral. Nas condiçóes do exercício arbitrário do poder burocrático, essa suspeita tem consequiências desastrosas.

“(...) no lugar das inúmeras liberdades [já] reconhecidas e duramente conquistadas (woblerworbene), [a burguesia] colocou unicamente a liberdade de comércio sem escrúpulos" (W. 4: 465; M: 69, grifado por Marx). Entende-se que objeto visa o Manifesto: o grande comércio liquida a liberdade do pequeno produtor. $O$ problema é que a liberdade burguesa náo se limita a isso. Ela tem uma expressáo em lei contendo certos "extratos" que interessa preservar. Mais adiante Marx e Engels dirão que acusam os comunistas de querer destruir a liberdade e a personalidade. Mas tratar-se-ia só de eliminar a liberdade e a personalidade burguesas. Muito bem. Só que o texto continua da seguinte maneira: "Por liberdade se entende, no interior das atuais relaçóes burguesas de produçáo, o livre comércio, a livre compra e venda. / Mas se o tráfico desaparece, desaparece também o livre tráfico. A fraseologia (Redensarten) sobre o livre tráfico, assim como todas as demais bravatas sobre a liberdade, de nossa burguesia, só têm sentido diante do tráfico vinculado, e os oprimidos moradores dos burgos da Idade Média; não têm [sentido] diante da supressão comunista do tráfico [da supressão], das relaçōes burguesas de produçāo e da própria burguesia (W. 4: 476; M: 82, grifado por RF). Vê-se que a partir do presente só há duas possibilidades: a sociedade burguesa e o comunismo. Há ainda as formas pré-burguesas ultrapassadas. Nesse contexto "as bravatas sobre a liberdade" só valem contra a situação passado. $O$ que significa, que não se pode utilizar o tema da liberdade para se defender de outras formas que não sejam as do passado: o que veio a significar, de formas de opressão pós capitalistas e anticapitalistas. De novo, Marx não pretendeu defender essas formas, simplesmente não pensou na sua possibilidade. Daí um discurso verdadeiro enquanto crítica da burguesia, mas instrumentalizável.

E para terminar esse ponto: "Quando o mundo antigo estava declinando, as antigas religióes foram vencidas pela religião cristã. Quando no século XVIII as idéias cristãs cederam diante das idéias do Aufklärung, a sociedade feudal travava a sua luta final com a burguesia então revolucionária. As idéias de liberdade de consciência e de liberdade religiosa só exprimiam a dominação da livre concorrência no campo da consciência (1872 e ed. posteriores: 'no campo do saber')" (W. 4: 480; M: 88, grifado por RF). A idéia de liberdade de consciência 
exprimia apenas - ainda exprime, apenas? - a livre concorrência no plano da consciência ou do saber. Eis o tipo de frase que, hoje, um socialista não pode pronunciar, sob pena de perverter inteiramente o seu projeto. Temos aí um formidável instrumento nas máos dos inimigos da "liberdade de consciência". De novo, entende-se o que Marx queria dizer. Em 1848 a frase náo tinha grandes inconvenientes imediatos, embora já nessa época, ou não muito mais tarde, alguns já previssem o que iria acontecer.

Finalmente, as dificuldades do Manifesto aparecem na parte III, na qual Marx e Engels fazem a crítica das outras formas de socialismo. Abrevio esse ponto para não prolongar excessivamente este texto. Gostaria de dizer alguma coisa sobre a crítica de Marx a três figuras, duas individuais e a terceira mais propriamente coletiva. Refiro-me ás críticas que ele faz a Proudhon (incluído no tópico "socialismo conservador ou burguês") e a Sismondi (no tópico "socialismo reacionário, na subdivisão "socialismo pequeno-burguês") e a crítica à filosofia alemã ("socialismo reacionário", subdivisão "socialismo alemão" ou socialismo "verdadeiro").

A propósito do "socialismo conservador ou burguês", o texto começa dizendo que "uma parte da burguesia deseja remediar os males (Misständen) sociais para garantir a existência da sociedade burguesa" (W. 4: 488; M: 94, grifado, respectivamente, pelos autores e por RF). "Como exemplo podemos citar a Philosophie de la Misère de Proudhon" (ib.). "Os burgueses socialistas querem as condiçóes de vida da sociedade moderna sem as lutas e os perigos que delas necessariamente decorrem. Querem a burguesia sem o proletariado (...) Quando [o socialismo burguês] convida o proletariado a realizar seus sistemas para entrar na nova Jerusalém, nada mais faz, fundamentalmente, do que dele exigir que permaneça na sociedade atual, mas renuncie à representaçáo odiosa que faz dela" (W. 4: 488; M: 4: 94, grifado por RF). Todo o problema desta crítica é saber o que se entende nesse contexto por "sociedade burguesa", "sociedade moderna" ou "sociedade atual". Porque são possíveis duas interpretaçôes. Ou "sociedade burguesa" é sociedade em que existe capital e, nesse caso, a crítica de Marx teria muita força. Mas talvez se trate - e é este em geral o caso de Proudhon - de querer conservar não uma sociedade em que subsiste o capital, mas uma sociedade em que subsistem mercadorias, ou certas esferas de troca. Ora, nesse caso, é difícil condenar sem mais o seu projeto. Se ele aparece como utópico para Marx e Engels, e porque eles só pensam na possibilidade de uma solução "catastrófica", no sentido indicado. Ora, se a idéia de conservar a mercadoria ou o dinheiro sem o capital pode ser discutida, já que a realização desse projeto não se faria sem dificuldade, o projeto de instauraçáo de uma comunidade transparente, na qual desaparecem todas as relaçóes mercantis e monetárias, aparece 
como ainda mais discutível e problemático. No universo de Marx esta última solução não seria utópica, porque a história traria esse resultado. Mas para além do projeto político de Marx, a idéia da conservação de certas relaçóes mercantis, neutralizando o capital, parece menos utópica do que a instauração da harmonia da transparência (ver a esse respeito, o posfácio do meu livro em francês, já referido). A dificuldade vem: da suposição de Marx de que não pode haver conservação de formas históricas (pelo menos de formas econômicas e políticas essenciais) na passagem do capitalismo ao socialismo; da ambigüidade do uso, nesse contexto, da noção de "sociedade burguesa".

A propósito de Sismondi, o problema é mais ou menos o mesmo. Se Marx e Engels consideram Proudhon um socialista burguês, eles reconhecem em gente como Sismondi a qualidade de defensores dos trabalhadores, ainda que Sismondi os defenda "do ponto de vista da pequena-burguesia" (W. 4: 484; M: 90). 0 Manifesto reconhece de resto os méritos do "socialismo pequenoburguês". "Ele pôs a nu as hipócritas apologias dos economistas. Demonstrou irrefutavelmente os efeitos destruidores da maquinária e da divisão do trabalho (...) [mostrou] a superprodução, as crises (...) a acintosa desproporção na distribuição das riquezas" etc. (W. 4: 484-485; M: 90-91). Seu erro é pretender "restabelecer os antigos meios de produção e de troca e com eles as antigas relaçóes de produção e de troca, ou então o de desejar aprisionar de novo, à força, os modernos meios de produção e de troca no quadro das antigas relaçóes de produçáo, que se fizeram explodir por aqueles, e que não podiam deixar de se fazer explodir. Em ambos os casos, tal socialismo é ao mesmo tempo reacionário e utópico" (W. 4: 485; M: 91) 0 problema é parecido com o anterior. Sismondi quer voltar ao passado? Mesmo que isto seja verdade, Marx o critica essencialmente por querer conservar relaçóes mercantis, ao mesmo tempo em que combate o capital. Por que essa solução seria necessariamente utópica, por que seria "reacionária"? Marx é injusto com Sismondi (embora fale dele em outros lugares em termos consideravelmente elogiosos). O projeto político de Marx - porque é disso que se trata - não aparece hoje como menos utópico do que o de Sismondi.

Em último lugar, a filosofia alemã, e a filosofia em geral. Já abordei a relação de Marx com a filosofia, neste texto e em outros. Nas passagens que vou considerar, ela reaparece na forma da crítica de uma modalidade de socialismo. Os filósofos e semifilósofos críticos alemães importam as idéias francesas que estão ligadas às condiçōes francesas, sem poder importar essas condições. $\mathrm{Na}$ Alemanha, a luta contra o absolutismo feudal apenas começa, e por isso "a literatura francesa perdeu todo significado prático imediato (...)" (W. 4: 485; M: 91). "Ela devia aparecer como especulação ociosa sobre a verdadeira sociedade 
(na ed. de 1872: 'omite-se sobre a verdadeira sociedade'), sobre a realização da essência humana". Segue-se uma comparação com a situação no século XVIII: "Do mesmo modo, para os filósofos alemães do século XVIII, as reivindicaçóes da primeira revolução francesa não foram mais do que reivindicaçôes da 'razão prática' em geral, e as manifestaçốes da vontade da burguesia revolucionária francesa expressavam a seus olhos apenas as leis da vontade pura, da vontade como deve ser da vontade verdadeiramente humana" (W. 4: 485-486; M: 91-92).

Os literatos alemães se apropriaram "das idéias francesas a partir do seu próprio ponto de vista filosófico" (p. 486-492). Como os monges da Idade Média que recobriam os manuscritos clássicos com histórias de santos (...) eles escreviam seus absurdos (Unsinn) filosóficos por detrás do original francês. (...) Por detrás da crítica francesa do Estado burguês escreveram 'alienação da essência humana', por detrás da crítica francesa do Estado burguês escreveram 'supressão do domínio do universal abstrato' e assim por diante. / Batizaram essa interpolaçáo da sua fraseologia filosófica (...) com o nome de 'filosofia da açáo', 'verdadeiro socialismo', 'ciência alemã do socialismo', 'fundamentação filosófica do socialismo' etc." (ib.).

Há aí dois aspectos: por um lado, Marx ataca os "semifilósofos" e "belos espíritos" alemães, que abundavam na época. Porém, há mais do que isto: o texto contém uma crítica geral da filosofia e uma teoria sobre o discurso filos6fico, que são aliás, em parte, autocríticas (cf. o Marx de 44). 0 discurso filosófico aparece como simples transposiçáo ilusória de discursos de alcance "prático". A segunda crítica kantiana, por exemplo, aparece, na figuraçáo clássica de simples tradução especulativa "ociosa" do discurso francês (mais adiante, ler-se-á que este e "castrado" pelos alemães). Ora, se é verdade que há uma correspondência entre Kant e a realidade revolucionária francesa, esse tipo de redução resumiria $o$ interesse do texto de Kant a um registro puramente histórico. A correspondência entre prática revolucionária francesa e ética kantiana existe, e esta última não é o modelo absoluto de todas as éticas. Mas ela interessa, hoje, como discurso ético, discurso que sem dúvida tem também implicaçóes políticas, mas implicaçōes que ultrapassam o universo de Marx e em parte se opõem à leitura que ele fez de Kant (ver a Dialética negativa de Adorno, por exemplo).

Quanto à tentativa de ridicularizar a "fundamentaçáo filosófica do socialismo", ela poderia ser legitimada enquanto visa certos semiteóricos e ideólogos da época. Mas o projeto de pensar filosoficamente o socialismo (talvez de fundamentá-lo filosoficamente) não tem nada de intrinsecamente "ideológico", após quase cem anos de violência e arbítrio em nome do socialismo. Hoje, inibir esse projeto filosófico não é mais questionar tal ou qual ideólogo; é servir aos 
interesses dos novos déspotas, diante dos quais a filosofia representa de novo - quem diria? - uma atividade crítica.

O Manifesto é um grande texto, que pertence ao melhor da tradição socialista. Mas 150 anos depois, é preciso manejá-lo com cuidado. Ele pode ser ainda um instrumento de análise e de combate. Porém, ele (ou parte dele) pode servir também - e com certa "base" - como ideologia de novas formas de exploração e de opressão. O pior que se poderia fazer hoje é transformá-lo naquilo que ele nunca foi: num texto religioso. Infelizmente esta transfiguração ainda ocorre em certos meios, com os resultados que conhecemos.

Notas

1 Marx-Engels, Werke, Berlin, Dietz Verlag, 1959, (abreviarei por W.), Band 4, respectivamente, p. 462, 480, 464, 479, 493 e 482. Manifesto do Partido Comunista, organização e introdução de Marco Aurélio Nogueira, tradução de Marco Aurélio Nogueira \& Leandro Konder (abreviarei por M), Petrópolis, Vozes, $8^{\mathrm{a}}$ ed., 1998, respectivamente, p. $66,85,68,84,99$ e 87 . Não retomei literalmente a boa tradução de Nogueira \& Konder, mas a consultei ao longo de todo o texto.

2 Há um texto que exemplifica bem a perspectiva quase-historicista da transição; é uma passagem bem conhecida da Ideologia Alemã: "O comunismo não é para nós um estado (Zustand) que deva ser criado, nem um ideal pelo qual a realidade se deve reger. Chamamos de comunismo o movimento efetivo (wirklich) que abole o estado atual. As condiçōes desse movimento resultam das pressuposiçóes atualmente existentes" (W. 3; trad. francesa dirigida por G. Badia, Paris, Ed. Sociales, 1968, p. 64). Na realidade, se o comunismo não é um ideal, ele também não é, na perspectiva de Marx, o simples movimento real que abole o modo de produção capitalista. $O$ verdadeiro estatuto do "comunismo" tal como o darão as obras de maturidade fica entre uma coisa e outra.

3 Essa passagem deve alguma coisa a uma discussão com Pablo Ortelado, graduando em filosofia. Não posso assinalar a cada passo o que devo às discussões com os alunos. Mas agradeço por tudo.

4 Esta é a solução proposta para a leitura do texto por Michael Lowy, em A teoria da revolução no jovem Marx (ainda inédito em português). Ver a edição em espanhol, Buenos Aires, Siglo Vientiuno, $2^{\mathrm{a}}$ ed., 1972, p. 220 e ss.

5 Ver Hal Draper, Karl Marx's theory of revolution, v. II, The politics of social classes. New York e Londres, Monthly Review Press, p. 196-200.

6 Ver H. Draper, op. cit., p. 198-200. O panfleto chama-se "Exigências do partido comunista na Alemanha". Salvo engano, ele não se encontra nas Werke. Draper o 
cita a partir de Dirk J. Struik, Birth of the Communist Manifest (...), New York, International Pub., 1971.

7 Bem entendido, não vai aí da minha parte nenhum elogio ao "anti-historicismo". $O$ marxismo clássico, que de resto não deixarei de criticar, não é nem historicista nem anti-historicista. Ver a esse respeito, o meu texto "Dialética marxista, historicismo, anti-historicismo". In: Marx. Lógica, História, tese de livre-docência, USP, 1989, publicado parcialmente em Marcelo Dascal (org.), Conhecimento, Linguagem, Ideologia, São Paulo, Perspectiva, 1989.

8 Ver, por exemplo, W. 4: 471; M: 75. W. 4: 490; M: 96. W. 4: 474; M: 80.

9 Hal Draper, op. cit., p. 615 e ss., insiste sobre o fato de que Marx se refere às velhas classes médias, às classes médias que existiram até aqui (bisherige) e que em outro texto (W. 4: 484; M: 90) ele se refere: a uma nova classe média cujo destino é um pouso mais complicado.

10 Observemos também que a análise da decadência das formas históricas é diversificada: as formas sociais terminam "ou com uma transformação (Umgestaltung) de toda a sociedade, ou com derrocada (Untergang) comum das classes em luta” (W. 4: 462; M: 66).

11 Também em W. 4: 477; M: 82; e em W. 4: 464; M: 68 (mas aqui em sentido material).

12 Ver a esse respeito meu livro Dialética marxista, dialética hegeliana: a produção capitalista como circulação simples. São Paulo, Paz e Terra/Brasiliense, 1997, apêndice, p. 150-153.

$13 \mathrm{O}$ texto só está publicado em francês: Le Capital et la Logique de Hegel (dialectique marxienne, dialectique hégélienne). Paris, l'Harmattan, 1997.

14 Há um texto, modificado por Engels, de onde se poderia tirar idéia de um progresso acumulativo de formas: "Cada um desses graus de desenvolvimento da burguesia foi acompanhado por um progresso político correspondente (W. 4: 464; M: 68). Engels neutraliza essa possibilidade, acrescentando a "progresso político" as palavras "dessa classe". Na parte final do Manifesto, as condiçōes políticas que a burguesia deve criar, uma vez obtido o poder, são consideradas como um progresso, mas enquanto elas representarão armas nas mãos da revolução.

Ruy Fausto é professor-emérito da FFLCH-USP e ensina na Universidade de Paris 8. 